\title{
TRATAMIENTO TRIBUTARIO DE MERMAS Y DESMEDROS EN RENTA Y EN EL IMPUESTO A LA RENTA ${ }^{1}$
}

\section{TAX TREATMENT OF WASTE AND LOSSES ON INCOME AND SALES TAX REGIMES}

\author{
Haydee Belito Soto ${ }^{2}$ \\ Universidad Femenina del Sagrado Corazón UNIFÉ \\ Lima-Perú. \\ https://orcid.org 0000-0002-5394-2080 \\ Haydee.belitos@unife.pe \\ Diana Mireya Burga Muñoz ${ }^{3}$ \\ Universidad Femenina del Sagrado Corazón UNIFÉ \\ Lima-Perú. \\ https://orcid.org/0000-0002-2734-7544 \\ Diana.burgam@unife.p
}

\section{RESUMEN}

En este trabajo se abordan nociones fundamentales respecto de las mermas y desmedros y su tratamiento tanto como en la Ley del Impuesto a la Renta y en la Ley General a las Ventas peruana. Asimismo, mediante el aporte de diversos informes emitidos por la Administración Tributaria peruana, se especifican a qué se le puede llamar mermas y desmedros para ser catalogados como gastos deducibles. Finalmente, a mayor abundamiento, se detallarán aspectos generales respecto de las mermas y desmedros estipulados en la legislación de otros países a manera Derecho Comparado.

\section{PALABRAS CLAVES}

Tributos, mermas, desmedros, gastos deducibles, legislación tributaria

\section{ABSTRACT}

This paper addresses fundamental notions regarding waste and losses and their treatment in both the Income Tax Law and the Peruvian General Sales Law (a.k.a. V.A.T.). Likewise, several reports issued by the Peruvian Tax Administration were used to define waste and losses and determine what may classify as deductible expenses. Finally, general aspects regarding waste and losses stipulated in the legislations of other countries are detailed in depth applying Comparative Law methods.

\section{KEYWORDS}

Taxes, waste, losses, deductible expenses, tax legislation

1 El presente artículo ha sido desarrollado en el curso de Derecho Tributario III, con el apoyo y asesoría del docente del curso Dr. Michael Zavaleta, Máster de Fiscalidad Internacional de la UCLM. DEA en Derecho Tributario Europeo por la UCLM. MBA UNIR España, y Doctor en Derecho por la Universidad de Castilla - La Mancha (UCLM), quien propuso su postulación para su publicación en la revista.

2 Estudiante del Noveno Ciclo del Semestre 2021-II de la Escuela Profesional de Derecho de la Universidad Femenina del Sagrado Corazón (UNIFĖ).

3 Estudiante del Noveno Ciclo del Semestre 2021-II de la Escuela Profesional de Derecho de la Universidad Femenina del Sagrado Corazón (UNIFÈ). 


\section{INTRODUCCIÓN}

Iniciamos en ese sentido preguntándonos lo siguiente: ¿Cómo se puede definir las mermas y desmedros en el marco de la normativa tributaria?

En términos generales, estos tópicos han sido desarrollados por distintos especialistas en la materia, ya que su tratamiento y aplicación resulta importante tanto para la Administración Tributaria como para los deudores tributarios.

Jiménez y Rivera (2019), precisan antecedentes que se debe tomar en cuenta cuando de mermas y desmedros se trata.

Las autoras precisan que en 1973 nace el IASC - International Accounting Standard Committee (Comité de normas internacionales de contabilidad), entidad encargada de emitir las Normas internacionales de Contabilidad (NIC), las cuales se crearon con la principal finalidad de que exista una homologación en la contabilidad a nivel mundial y de esta manera todos los usuarios tendrían la facilidad de entender la información financiera. (p. 1).

Posterior a ello, Jiménez y Rivera (2019) establecen que en 1993 se emitió la "NIC 2 Existencias", la cual estuvo vigente hasta el 31 de diciembre del 2005, luego se emite la NIC 2 Inventarios (modificada), la cual entra en vigencia a partir del 1 de enero del 2006, cuyo objetivo de esta norma financiera es prescribir el tratamiento contable de los inventarios y cómo deben medirse los inventarios.

Ahora bien, ¿por qué la importancia de la creación de dicho comité y de normas de tratamiento internacional? La interrogante anterior es respondida por las autoras al momento de reconocer que la interiorización de la estructura de costos en una empresa a nivel general es vital, debido a que de esta forma se pueden controlar y pueden proyectar la rentabilidad que van a obtener, así como también de esta forma, se puede proyectar el impacto tributario que puede acaecer.

Precisado lo anterior, se puede evidenciar que la contabilidad y el inventario en una empresa es imprescindible para los empresarios, por lo que es necesario tener el control de lo que ingresa, de lo que egresa, así como también de las pérdidas físicas o deterioros propios del proceso de naturaleza de cada producto que forma parte de los activos de las empresas, para luego rendir cuentas a la Administración Tributaria.

Es en tal sentido que, el ordenamiento jurídico peruano ha atendido esta necesidad y la reconoce dentro de la normativa tributaria nacional, específicamente en la Ley del Impuesto a la Renta (en adelante la "LIR") en concordancia con su Reglamento.

Como segundo punto dentro del presente trabajo de investigación se desarrolla el tratamiento tributario de mermas y desmedros en el Impuesto General a las Ventas (IGV), por lo que se ha dado a conocer como parte introductoria el funcionamiento del IGV en nuestro país, refiriéndonos a las normativas que hicieron posible su debida aplicación, asimismo se ha considerado opiniones de autores que desde su punto de vista conceptúan el IGV, y de la forma cómo el IGV se desarrolla y como antesala colocamos que las mermas y desmedros son parte importante de las existencias, porque son las mermas y desmedros los que determinarán el saldo del stock de mercaderías e inventarios, dependiendo de uso y manejo de estos, en consecuencia siempre van a existir en una industria y a partir de estas premisas mostramos ejemplos de la aplicación de mermas y desmedro 
en el IGV, viendo así la posibilidad acorde a ley de poder acreditarlas para deducirlas. Finalmente se considera explorar la legislación comparada entorno a este tema tan importante.

\section{DEFINICIÓN DE MERMAS Y DESMEDROS A LA LUZ DE LA LEGISLACIÓN PERUANA.}

Para poder entender la importancia y la determinación de las mermas y desmedros, es importante tener en cuenta conceptos básicos y fundamentales que operan dentro de la LIR.

Asimismo, es importante definir uno de los conceptos preliminares que es la Renta Neta, que en palabras de Ynca y Gonzáles (2017), son el resultado de deducir de la Renta Bruta, los gastos necesarios para producir y mantener su fuente productora mientras que la deducción no se encuentre expresamente prohibida por la Ley.

Precisado lo anterior, las autoras traducen el concepto y sostienen que la deducibilidad de los gastos estará condicionada a la relación que estos tengan con la necesidad en que se deba incurrir en ellos a fin de permitir el funcionamiento y continuidad de las actividades generadoras de Renta. .

Es por lo mencionado que, a partir de ello, el artículo $37^{\circ}$ de la LIR, establece los principales gastos deducibles donde se incluyen a los gastos generados por pérdidas en el inventario entendiéndose como tales a las mermas y desmedros, con la finalidad que el deudor tributario pueda tributar menos en relación a las mermas y desmedros considerados como gastos deducibles.

El artículo 21 del Reglamento de la LIR, específicamente en el inciso c), precisa lo siguiente:

"1. Merma: Pérdida física, en el volumen, peso o cantidad de las existencias, ocasionada por causas inherentes a su naturaleza o al proceso productivo.

A mayor abundamiento, Actualidad Empresarial (2011), define que:

“(...) La merma, desde el punto de vista técnico, como las pérdidas físicas tanto en el volumen, peso o cantidad de los materiales, o existencias durante los procesos productivos, comerciales u operativos que se manifiestan en las diferencias de inventario, por cuanto, las mermas cuantitativas son inherentes a los procesos indicados, debido a sus condiciones naturales y de operación" (Revista de Investigación y Negocios).

A su turno Ferrer (2010), clasifica a las mermas en normales y anormales, cuyas definiciones pueden considerarse como:

1. Merma Normal: En el proceso productivo, las empresas industriales fijan porcentajes de pérdidas por merma normal de las materias primas o suministros que se consumen en la producción de sus productos, que se consideran en por esa razón normales, estas mermas se aplican al costo de los productos elaborados en proporción al volumen de producción, es decir las pérdidas por esta clase de mermas será asumida por el costo de producción.

2. Merma Anormal: Aquellas mermas que se producen en el proceso de producción cuyos valores exceden los montos estimados considerados normales, estas pérdidas no formarán parte del costo de los productos elaborados, estas pérdidas deben ser asumidas como gasto del periodo. 
Ahora bien, respecto a "Desmedro", el inciso c) del artículo 21 de la LIR, lo define como la "pérdida de orden cualitativo e irrecuperable de las existencias, haciéndolas inutilizables para los fines a los que estaban destinados"

Actualidad Empresarial (2010), establece los siguientes ejemplos respecto a desmedros:

a) Las medicinas que tengan sus fechas de vencimiento prescritas.

b) Las prendas de vestir de dama y caballero que por el tiempo hayan pasado de moda.

c) Las máquinas de escribir con la aparición de las computadoras quedaron en desuso.

d) Los disquetes quedaron en desuso ante la aparición de los CD en el mercado; y posteriormente, este último fue superado por la aparición del USB.

\section{TRATAMIENTO TRIBUTARIO DE LAS MERMAS Y DESMEDROS EN EL PERÚ.}

Teniendo los conceptos preliminares de manera detallada, conviene precisar cuál es el tratamiento que se le debe dar a las mermas y desmedros para ser considerados como gastos deducibles.

El inciso f) del artículo 37 de la Ley del Impuesto a la Renta, cuyo Texto Único Ordenado ha sido aprobado por el Decreto Supremo $N^{\circ}$ 179-2004-EF, establece que, son deducibles los desmedros de existencias debidamente acreditados. En ese mismo sentido, el inciso c) del artículo 21 del Reglamento de la Ley del Impuesto a la Renta, aprobado por el Decreto Supremo $N^{\circ} 122-94-E F$, prevé que, tratándose de los desmedros de existencias, la Superintendencia Nacional de Aduanas y de Administración Tributaria (en adelante la "SUNAT"), aceptará como prueba la destrucción de las existencias efectuadas ante Notario Público o Juez de Paz, a falta de aquel, siempre que se comunique previamente a la SUNAT en un plazo no menor de seis (6) días hábiles anteriores a la fecha en que se llevará a cabo la destrucción de los referidos bienes, siendo que dicha entidad podrá designar a un funcionario para presenciar dicho acto.

Es por lo mencionado, que la Administración Tributaria peruana, para la deducción de mermas y desmedros de existencias, establece en el artículo 21 del Reglamento de la LIR -artículo modificado el 20 de abril de 2020, mediante Decreto Supremo № 086-2020-EF- lo siguiente:

a) El contribuyente deberá acreditar las mermas mediante un informe técnico emitido por un profesional independiente, competente y colegiado o por el organismo técnico competente. Dicho informe deberá contener por lo menos la metodología empleada y las pruebas realizadas. En caso contrario, no se admitirá la deducción.

b) Tratándose de los desmedros de existencias, la SUNAT aceptará como prueba la destrucción de las existencias efectuada ante Notario Público o Juez de Paz, a falta de aquél, siempre que el acto de destrucción se comunique previamente a la SUNAT en un plazo no menor de dos (2) días hábiles anteriores a la fecha en que se llevará a cabo la destrucción de los referidos bienes.

c) Cuando el costo de las existencias a destruir sumado al costo de las existencias destruidas con anterioridad en el mismo ejercicio sea de hasta de diez (10) UIT, la SUNAT aceptará como prueba la destrucción de las existencias sustentada en un informe que debe contener la siguiente información, siempre que el acto de destrucción se comunique previamente a la SUNAT en el plazo señalado en el párrafo anterior. Dicho informe debe contener lo siguiente: 
i) Identificación, cantidad y costo de las existencias a destruir.

ii) Lugar, fecha y hora de inicio y culminación del acto de destrucción.

iii) Método de destrucción empleado.

iv) De corresponder, los datos de identificación del prestador del servicio de destrucción: nombre o razón social y RUC.

v) Motivo de la destrucción y sustento técnico que acredite la calidad de inutilizable de las existencias involucradas, precisándose los hechos y características que han llevado a los bienes a tal condición.

vi) Firma del contribuyente o su representante legal y de los responsables de tal destrucción, así como los nombres y apellidos y tipo y número de documento de identidad de estos últimos.

d) A efecto de que la SUNAT acepte como prueba la destrucción de las existencias sustentada en el referido informe, este debe ser presentado a dicha superintendencia en la forma, plazo y condiciones que esta establezca.

e) La SUNAT podrá designar a un funcionario para presenciar el acto de destrucción mencionado en los párrafos precedentes, así como establecerá la forma y condiciones para la presentación de las comunicaciones del acto de destrucción.

f) Dicha entidad también podrá establecer procedimientos alternativos o complementarios a los indicados, tomando en consideración la naturaleza de las existencias o la actividad de la empresa o situaciones que impidan el cumplimiento de lo previsto anteriormente.

g) La destrucción de existencias que se realice se debe acreditar con el informe a que refiere el artículo 21 del Reglamento de la LIR, siempre que el acto de destrucción se comunique previamente a la dirección de correo electrónico: comunicaciones_desmedros@sunat.gob. pe en un plazo no menor de dos (2) días hábiles anteriores a la fecha en que se llevará a cabo dicha destrucción.

h) En tanto no se establezca la forma y condiciones para la presentación de las comunicaciones del acto de destrucción a que se refiere el inciso c) del artículo 21 del Reglamento de la Ley del Impuesto a la Renta, dicha presentación deberá realizarse en las dependencias de la SUNAT.

i) En tanto no se establezca la forma, plazo y condiciones para la presentación del informe a que se refiere el cuarto párrafo del inciso c) del artículo 21 del Reglamento de la Ley del Impuesto a la Renta, este deberá presentarse en las dependencias de la SUNAT dentro de los cinco (5) días hábiles siguientes a la destrucción de las existencias.

La LIR y su Reglamento establece el procedimiento que debe seguir el deudor tributario para la deducción de gastos de mermas y desmedros, sin embargo, es importante resaltar que la Administración Tributaria debe acoger cada caso en concreto para determinar la naturaleza del tributo, todo ello, en atención al principio de Reserva de Ley.

Es en tal sentido que, el Tribunal Constitucional mediante la Sentencia $N^{\circ}$ 2762-2002- AA/TC Fundamento $N^{\circ} 9$ señala que la Reserva de Ley en materia tributaria debe ser analizada según dos planos uno horizontal y otro vertical y lo expresa mediante el siguiente texto:

“(...) Este Tribunal, sin embargo, advierte que estas exigencias deben ser analizadas en cada caso concreto y dependiendo de la naturaleza del tributo, pues el contenido material 
de la reserva de ley requerirá una concretización singular en atención a la naturaleza y objeto de cada cobro tributario. Esta determinación o intensidad de la reserva se logra cuando se parte de un análisis de la reserva de ley tanto en su extensión horizontal como vertical."

\section{INFORMES DE SUNAT RESPECTO DE MERMAS Y DESMEDROS.}

Es por lo mencionado, que la Administración Tributaria ateniendo el citado principio, mediante diversos Informes, ejemplifica de acuerdo a casos en concretos, cuando una situación de hecho califica como desmedro o merma, y estos a su vez, puede considerarse como gasto deducible al hecho imponible:

a) Informe $N^{\circ}$ 064-2014-SUNAT/5D0000: Rotura de existencias de un hotel califica como desmedro.

"Para efectos del Impuesto a la Renta, las roturas de las existencias de un hotel que impliquen solo una pérdida en la calidad de dichos bienes que impide que puedan seguir siendo utilizados para los fines a los que estaban destinados, califican como desmedros. A la fecha no existe norma jurídica alguna emitida por la SUNAT que haya aprobado un procedimiento específico que sea de aplicación al supuesto a que se refiere el numeral anterior, por lo que resulta de aplicación a este el procedimiento general establecido en el inciso c) del Artículo $21^{\circ}$ del Reglamento."

b) Informe: $\mathrm{N}^{\circ}$ 009-2006-SUNAT/2B0000. Pérdidas sufridas en productos a granel califican como merma.

“Tratándose de operaciones de importación de productos a granel transportados al país por vía marítima, en las cuales existen diferencias entre la cantidad del producto comprado y embarcado en el exterior y recibido en el país, considerando que dicha diferencia detectada al momento del desembarque corresponde a condiciones de humedad propias del traslado se tiene que: La pérdida física sufrida en productos a granel, que corresponda a condiciones del traslado que afectan los bienes por las características de estos como ocurre con la humedad propia del transporte por vía marítima, califica como merma."

c) Informe: $N^{\circ}$ 129-2005-SUNAT/2B0000: Merma por pérdidas de electricidad no es aplicable para efectos del Impuesto a la Renta.

“El concepto de merma para efecto del IGV, precisado en el inciso a) de la Primera Disposición Transitoria y Final del Decreto Supremo N 064-2000-EF, referido a las pérdidas de electricidad, no es aplicable para efectos del Impuesto a la Renta, el cual tiene un concepto específico de merma."

d) Informe: $N^{\circ}$ 200-2016- SUNAT/5D0000: La putrefacción de productos perecibles durante el proceso de producción califica como desmedro.

“Para efectos del Impuesto a la Renta, la putrefacción de frutas y/o verduras, ocurrida durante el proceso de producción, en tanto que implica una pérdida de la calidad de dichos bienes que impide que puedan ser utilizados para los fines a que estaban destinados, califica como desmedro. Las empresas productoras de frutas y/o verduras que son 
proveedoras de autoservicios, así como exportadoras de estos bienes, no pueden utilizar el procedimiento alternativo regulado en la Resolución de Superintendencia N 243-2013 / SUNAT para acreditar el desmedro de dichos bienes."

\section{TRATAMIENTO TRIBUTARIO DE MERMAS Y DESMEDROS RESPECTO DEL IMPUESTO GENERAL A LAS VENTAS}

Ahora conozcamos el tratamiento tributario de mermas y desmedros en IGV, para desarrollar la presente investigación, es importante conocer el tratamiento del IGV peruano, y como primer término referirnos a la normatividad que hace posible su actuación, ya que éstas han pasado por diversas modificaciones desde la Ley $N^{\circ} 9923$ Ley de Timbre y Papel Sellado publicada el 15 de enero de 1994, hasta el Nuevo Texto de la Ley del Impuesto General a las Ventas e Impuesto Selectivo al consumo Decreto Legislativo No 821, aprobado por Decreto Supremo 055-99-EF publicado el 15 de abril de 1999, régimen vigente hasta la fecha. Además, cabe indicar que la imposición al consumo en el país está constituida por dos impuestos: el Impuesto General a las Ventas y el Impuesto Selectivo al Consumo. Por lo que únicamente abordaremos el impuesto general a las ventas en el tratamiento de mermas y desmedros, conozcamos ahora las definiciones que nos brinda la doctrina en relación al impuesto general a las ventas; en ese sentido citamos a Bravo (s.f, p. 31) quien sostiene:

El Impuesto General a las Ventas (IGV) es un impuesto plurifásico estructurado en base a la técnica del valor agregado, bajo el método de sustracción, adoptado como método de deducción el de base financiera, en mérito del cual el valor agregado se obtiene por la diferencia entre las "ventas" y las "compras" realizadas en el periodo, vale decir, no se persigue la determinación del valor agregado económico o real de dicho periodo, el cual se obtendría de optarse por el método de deducción sobre base real. Respecto del sistema para efectuar las deducciones, sobre base financiera, adopta el de impuesto contra impuesto; es decir, que la obligación tributaria resulta de deducir del débito fiscal (impuesto que grava las operaciones realizadas) el crédito fiscal (impuesto que grava las adquisiciones realizadas)

Asimismo, se cita a Alva y Ramos (2020) detalla que:

Que el impuesto general a las ventas (IGV) es un impuesto indirecto que grava el consumo de bienes y servicios (...) asimismo, el IGV se encuentra estructurado para gravar el valor agregado en cada etapa del proceso producción y comercialización de bienes y servicios; es decir, el fisco obtiene una porción del impuesto determinado por el contribuyente en cada una de las etapas señaladas, deduciendo de su impuesto bruto el crédito fiscal originado por el impuesto que gravó sus adquisiciones (p.453)

Se ha visto importante citar a los autores, para llegar a comprender y colegir que el modelo peruano está basado en modelo impositivo al consumo en etapas múltiples y no acumulativo tipo IVA, esto quiere decir que se grava todas las ventas en las distintas etapas de la cadena de producción de bienes y servicios y será el impuesto al valor agregado o valor añadido que se pagará a la SUNAT como ente recaudador.

Al respecto, Villanueva manifiesta:

Para aquellos sujetos que están gravados con el IGV se relaciona básicamente 2 instituciones jurídicas que están reguladas en la ley: la primera relación jurídica de traslación o relación jurídica de repercusión artículo 38 de la ley de IGV, en virtud de 
la cual el vendedor o el prestador de servicios, traslada el IGV al cliente, sea comprador o sea usuario del servicio. Y el artículo 38 del tercer párrafo de la ley del IGV señala que: el comprador o usuario del servicio está obligado a aceptar el traslado económico del impuesto. De modo tal quien efectúa una venta o quien presta un servicio tiene la facultad legal de trasladar económicamente el impuesto al cliente. Por su parte el cliente que tiene que pagar un IGV de compras tiene una segunda relación jurídica que es el derecho al crédito fiscal. El comprador de los bienes por el contrario tiene derecho a deducir el IGV que ha pagado como crédito fiscal.

En estas relaciones jurídicas tributarias, claramente podemos observar que el IGV se desenvuelve en el uso del crédito fiscal y la traslación del impuesto, y el escenario de actuación del IGV se da en el mercado, porque es allí donde se realizarán las compras y ventas de productos y/o servicios; y quien pone en funcionamiento al mercado es precisamente uno de los agentes económicos: las empresas que pueden ser personas jurídicas o personas naturales. Estas actuaciones están principalmente reguladas por nuestra Constitución Política del Perú, artículo 58, en ella también se regula la autonomía privada articulo 14 y 62, además de la regulación especial vigente antes mencionada. Permitiendo que estas acciones se enmarquen dentro de una economía social de mercado, haciendo que por el lado de las empresas (sujetos del impuesto) no recaiga la carga económica del IGV, cuidando su margen de ganancia, siendo pues la carga económica una facultad legal y no de libre albedrio aplicada al consumidor.

En ese orden de ideas, nos adentraremos en el tratamiento tributario de las mermas y desmedros en la aplicación del IGV, direccionado hacia las personas jurídicas mercantiles, personas jurídicas sin fines de lucro y toda persona natural, etc. (artículo 9 de la Ley del Impuesto a las Ventas) y cómo estos enfrentan o asumen las pérdidas cualitativas o cuantitativas en sus productos de acuerdo a la actividad comercial a la cual se dedican, para ello el término de existencias cobra importancia en esta sección de la investigación, en esa medida se menciona a las Normas Internacionales de Contabilidad NIC 2 Inventarios, definiciones 6:

Inventarios son:

a) Mantenidos para ser vendidos en el curso normal de la operación

b) En proceso de producción con vistas a esa venta; o

c) En forma de materiales o suministros, para ser consumidos en el proceso de producción, o en la prestación de servicio

En efecto, desde el ámbito del IGV las mercaderías o existencias tienen que estar gravadas con el $18 \%$. En consecuencia, Alva y Ramos (2020) nos aclaran que "la tasa del impuesto general a las ventas es de (16\%) a la cual se le debe sumar el IPM (2\%), sumada ambas corresponderán al (18\%) la tasa que se debe aplicar" (p.481).

Se comprende entonces, que las existencias vienen hacer los inventarios, es decir aquellos bienes que cuenta la empresa como parte de su mercadería, decíamos que las existencias cobran importancia, ya que al usar las existencias lo que acontece posterior como consecuencia serán las mermas y desmedros que estos sufran, cuando nos referimos al uso de las existencias aludimos al uso y manejo que estos podrían tener, los que determinarán una merma o desmedro, y hasta se podría decir que las existencias es el objeto de estas figuras que estamos describiendo, para ello lo vamos a enfocar desde el ámbito del IGV. 
Es ese sentido, las mercaderías podrían sufrir mermas o desmedros en el proceso productivo y en el proceso de comercialización respectivamente y su consecución traslado al almacén o lugar que tiene el comprador, resultando que dependiendo del producto y las pérdidas que estas puedan tener, serán consideradas como mermas o desmedros, como por ejemplo en el caso de las mermas las perdidas van a ser producto de causas naturales que tiene el mismo, es por ello que se dice que son perdidas cuantitativas, mientras que el desmedro es debido a que el producto ha quedado inutilizado u obsoleto por lo que su uso ya es irremediable, considerado como perdida cualitativa.

Entorno a estas premisas indicadas, las mermas y desmedros se van a desarrollar bajo el tipo de contrato de venta que puedan pactar las partes: empresa y el proveedor. Aquí algunos ejemplos:

Si se trata de una venta al contado:

a) En la compra de $1000 \mathrm{~kg}$ de trigo, el trayecto será de Cañete a Lima, y llegando a Lima no viene con el peso que se solicitó, pues vino con $980 \mathrm{~kg}$. perdida que pudo haber sido por circunstancias climáticas, deshidratación del producto, etc. Aquí lo que ocurrió es que este producto ha sufrido una merma, aquel peso que fue perdido, es decir, la diferencia que es $20 \mathrm{~kg}$, viene hacer la merma.

Como es pago al contado del producto, aquí el proveedor ya emitió su comprobante de pago respectivo al comprador, por lo que el pago del producto ya se ha realizado incluido el IGV, porque tributariamente aquí está cancelado y cerrado el IGV, debiendo asumir el comprador las mermas surgidas.

También puede surgir la merma, cuando ya habiendo recibido el comprador los productos, éste lo tiene en su almacén por varios días, entonces eso se califica como merma y lo asume el comprador debido a diversas alteraciones que pudiera tener el producto debido a que: no lo utilizaste, no lo vendiste, no hay clientes, etc. quedando tal merma a responsabilidad de él.

Si se trata de una venta al crédito:

b) Aquí también va a tener que ver mucho lo que las partes pacten: cuotas de pago, lugar de entrega, si varían los kilos en el producto, el pago será acorde a lo que llegue al almacén, o si hubiere mínimas diferencias puede que el proveedor reciba el pago intacto y así otros acuerdos de las partes, recordemos la libertad contractual.

Comprendamos que, si es venta al crédito, se infiere que ya se ha emitido un comprobante de pago, pero que no se colocado aun el IGV, puesto que recién se va a contabilizar cuando se haga entrega del producto, y el IGV (18\%) se va a calcular con el subtotal del precio, puesto que el subtotal va a variar dependiendo de cómo llegue la mercadería y acorde a lo que las partes han acordado.

Por ejemplo: empresa solicita $1000 \mathrm{~kg}$ de mandarinas, a proveedor, pero en el traslado solo llega $900 \mathrm{~kg}$, esa diferencia que viene hacer $100 \mathrm{~kg}$ viene hacer la merma del comprador, entonces como han acordado pagar por la cantidad de kilos de mandarinas que logre llegar al almacén, es decir los $900 \mathrm{~kg}$ y ya no los $1000 \mathrm{~kg}$. Por este monto facturará el proveedor y ahí se aplica recién el IGV. 
Si se trata de una venta en consignación:

c) Supongamos que una empresa es productora de zapatillas, y deja su producto en una tienda determinada y en determinados días regresa por el cobro de aquellos productos, es decir la empresa productora dejó 900 pares de zapatillas, pero 880 son para la venta y 20 para la muestra, por lo que no se ha facturado solo se emitió una guía de remisión, pero resulta que la consignataria no vendió las 880 , únicamente vendió 800 , entonces tiene un desmedro de 80 pares, más 20 pares de muestra; en ese sentido se tiene que anular la guía de remisión, hacer una nueva, y emitir finalmente una factura en la que se expresa el costo como subtotal y el IGV consiguientemente. Y el que asume el desmedro en este tipo de venta es el consignante para su deducción de gasto.

Y así podemos ir ejemplificando con otros tipos de ventas y también otros tipos de productos que tenga como giro la empresa, y como hemos podido apreciar de los tres ejemplos, es crucial saber en qué momento vamos a gravar el IGV (artículo 4 inciso a. del Texto Único Ordenado de la ley del Impuesto General a las Ventas - Decreto Supremo Nº05-99-EF), asimismo el tiempo en el que se va a dar el IGV va ser un momento posterior, porque una vez que se determina las mermas o desmedros que resulten de los productos y según los productos, la empresa puede optar por: vender aquellos productos o deducirlo como gasto, si lo vende va consignarse el IGV por lo que el producto será gravado, si opta como deducción de gasto, no estará sujeto a IGV, en consecuencia no habrá IGV que pagar, serán deducibles así lo estipula el articulo 37 literal f del Texto Único Ordenado de la Ley del Impuesto a la Renta: "las depreciaciones por desgaste u obsolescencia de los bienes de activo fijo y las mermas y desmedros de existencias debidamente acreditados, de acuerdo con las normas establecidas en los artículos siguientes". Y se menciona a la Ley del Impuesto a la Renta, en esta sección, porque lo que norma esta ley en el tema de mermas y desmedros será aplicables para el IGV.

Entonces lo idóneo o lo que le conviene a la empresa es deducir aquellos gastos, pero para ello tendrá que acreditarse, cumplir con ciertos requisitos regulados por ley, es así que el artículo 21 inciso c. párrafo 2 del Reglamento de la Ley del Impuesto a la Renta, sostiene:

"Cuando la SUNAT lo requiera, el contribuyente deberá acreditar las mermas mediante un informe técnico emitido por un profesional independiente, competente y colegiado o por el organismo técnico competente. Dicho informe deberá contener por lo menos la metodología empleada y las pruebas realizadas. En caso contrario, no se admitirá la deducción

Tratándose de los desmedros de existencias, la SUNAT aceptará como prueba la destrucción de las existencias efectuada ante Notario Público o Juez de Paz, a falta de aquél, siempre que el acto de destrucción se comunique previamente a la SUNAT en un plazo no menor de dos (2) días hábiles anteriores a la fecha en que se llevará a cabo la destrucción de los referidos bienes (...)"

Finalmente, todas las perdidas cuantitativas y cualitativas, llamadas mermas y desmedros respectivamente de las existencias o mercadería, existen legalmente para coadyuvar a la empresa en la deducibilidad del gasto, ya que, en el espacio de las comercializaciones, los productos nunca serán íntegros, por más que así se desee, pues surgen precisamente estas pérdidas, deterioros, inutilizaciones, obsolescencias, etc., durante la vida material de estas existencias, en cuanto a la calidad y cantidad de un producto. Es pertinente del mismo modo mencionar a este principio tan 
importante como lo es el principio de causalidad, porque al deducir gastos lo que va ocasionar es que estos gastos son necesarios acreditarlos, porque eso hará que la empresa no se vea perjudicada pagando IGV, y esta deducción hará que las empresas sigan manteniendo su actividad económica, manteniendo su fuente productora.

\section{DERECHO COMPARADO}

Entorno a mermas y desmedros en la legislación comparada, a efectos de no enmarcarnos dentro de nuestro ámbito interno nacional, conozcamos el tratamiento tributario de las mermas y desmedros en otros países, para ello citamos a Narváez, J (2018):

En BOLIVIA, el tratamiento tributario de las mermas y desmedros en existencias de toda empresa productiva, en nuestra legislación ocupa un lugar polémico toda vez que el Decreto Supremo No 24051 (Reglamento del Impuesto sobre las Utilidades de las Empresas), no efectúa una distinción entre ambos conceptos, limitándose este a establecer requisitos al desuso u obsolescencia de activos fijos y mercancías (...) Articulo 30 "los bienes del activo fijo y las mercancías que queden fuera de uso u obsoletos serán dados de baja en la gestión en que el hecho ocurra" (p.21)

También indica el autor que para que se haga posible aquella deducibilidad del gasto de estos bienes comunicará a la Administración Tributaria boliviana, dentro de los 10 días hábiles antes de proceder a la baja del bien que indica el reglamento, presentando consigo la lista de aquellos bienes, sus características, y cualidades, fechas de adquisición, costo del bien, y otros. Y que en tal sentido la Administración Tributaria designa a 2 funcionarios de la misma en presencia de un Notario que dará fe del acto, el Notario será elegido por la empresa solicitante, para luego proceder a la destrucción.

Al respecto Tapia, L. (2014) en sus tesis nos da a conocer cómo funcionan las mermas en el país de Chile:

Desde la perspectiva tributaria la "Circular N³, de 1992" del S.I.I. analiza el tratamiento de las mermas de mercaderías frente a la Ley del Impuesto al Valor Agregado (IVA) y la Ley de Impuesto a la Renta. El contribuyente debe llevar un cuidadoso registro de las mermas que se produzcan, así como contar también con los antecedentes necesarios para poder justificarlas ante el requerimiento de la autoridad tributaria. Si dichas mermas no son posibles de justificar, esto tendría efectos tanto respecto del Impuesto al Valor Agregado como respecto al Impuesto a la Renta. (p.72)

Tapia indica además en su tesis, que ante situaciones de caso fortuito o fuerza mayor no es necesario dar aviso a la SII, pero que si es necesario que tengan o deben anotar cronológicamente las mermas en el sistema de inventarios permanente o tarjeta de existencias, lo que si realizan es hacer la respectiva denuncia ante cualquier evento que pueda suscitarse, y que posteriormente serán ratificadas por un juzgado, concluye que para que estas mermas sean aceptadas como gasto, se deben acreditar mediante un informe técnico realizado por un profesional independiente, competente y colegiado. En tal sentido este informe deberá constar la metodología que se está usando, y las pruebas pertinentes que indique que hubo merma, de lo contrario no podrá realizarse la deducción. 


\section{CONCLUSIONES}

De todo lo desarrollado, se concluye lo siguiente:

1. Sera necesario que se pueda evidenciar en la contabilidad y el inventario en una empresa es imprescindible para los empresarios, por lo que será necesario tener el control de lo que ingresa, de lo que egresa, así como también de las pérdidas físicas o deterioros propios del proceso de naturaleza de cada producto que forma parte de los activos de las empresas, para luego rendir cuentas a la Administración Tributaria.

2. Asimismo, las empresas industriales, a lo largo de un proceso productivo van a generan mermas y desmedros que son difíciles de cuantificar; los primeros son sustentadas ante SUNAT mediante un informe técnico emitido por un profesional independiente, calificado y competente, de acuerdo con los requisitos exigidos por el Reglamento de la Ley del Impuesto a la Renta, y así será válido para poder sustentar como un gasto deducible; y en el caso de los desmedros, las empresa industriales deben identificar y comunicar a la SUNAT según lo el RLIR y estos se acreditan con la destrucción de las existencias efectuadas ante Notario Público o Juez de Paz.

3. Las mermas y desmedros en el Impuesto General a las Ventas, ayuda a que las organizaciones comerciales logran tener un equilibrio en cuanto a las perdidas cualitativas o cuantitativas que puedan sufrir los productos en los cuales ellos se dediquen, de tal forma que puedan deducirlos y continuar con sus procesos productivos o de comercialización en la satisfacción del comercio que ellos generen, para ello las empresas deben estar dotadas de conocimiento tanto de la ley, de las características propias de sus productos, a fin de que tanto el fisco como la empresa vayan en la misma dirección, de que se brinde una mejor venta de conformidad con las leyes tributarias.

4. La investigación desarrollada ha permitido comprender cómo es el funcionamiento de las mermas y desmedros del IGV en el Perú, si bien el IGV la vamos a asociar siempre en que la carga económica la va a tener el consumidor final, sin embargo, en cuanto a las mermas o desmedros los que asumen la carga son los proveedores o compradores, y va depender mucho el tipo de contrato en el cual estos se encuentren.

\section{REFERENCIAS}

- Actualidad Empresarial. (2011). ¿Cuál es el tratamiento tributario de las mermas y desmedros de existencias? http://www.aempresarial.com/web/revitem/1_12179_08664.pdf.

- Alva, M; Ramos, G. (2020). Manual Tributario. Primera Édición - agosto 2020. Pacífico Editores S.A.C

- Bravo, J (s.f). La Imposición al Consumo en el Perú Algunos Comentarios en Torno a los Efectos del IVA en el caso de Servicios. Revista Derecho y Sociedad. Universidad Pontificia Católica del Perú. https://revistas. pucp.edu.pe/index.php/derechoysociedad/article/view/16910/17216

- Código Tributario (2020). Texto Único Ordenado de la Ley del Impuesto General a las Ventas e Impuesto Selectivo al Consumo. Decreto Supremo No 055-99-EF. Articulo 22 Reintegro del crédito fiscal.

- Decreto Supremo No 086-2020-EF. (2020). https://busquedas.elperuano.pe/normaslegales/ modifican-el-reglamento-de-la-ley-del-impuesto-a-la-renta-decreto-supremo-no-086-2020ef-1865658-2/ 
- Ferrer, A. (2010). Mermas y Desmedros, Criterios contables y Tributarios. Actualidad Empresarial. http://aempresarial.com/web/revitem/5_11555_24429.pdf

- Gamba, C. (2014). I Foro Internacional de Tributación y contabilidad, Reserva de ley y normas contables, breves apuntes para una polémica.

- Informe $\mathrm{N}^{\circ}$ 129-2005-SUNAT/2B0000 (SUNAT 17 de junio de 2005).

- Informe $\mathrm{N}^{\circ}$ 09-2006-SUNAT/2B0000 (SUNAT 11 de enero de 2006).

- Informe N. ${ }^{\circ}$ 064-2014-SUNAT/5D0000 (SUNAT 24 de septiembre de 2014).

- Informe $\mathrm{N}^{\circ}$ 200-2016- SUNAT/5D0000 (SUNAT 26 de diciembre de 2016).

- Jiménez , A., \& Rivera, E. (2019). Mermas y Desmedros- Impacto financiero y tributario en las empresas del sector manufactura (actividades de impresión) en la Zona Este y Lima, 2017.https://repositorioacademico.upc.edu.pe/bitstream/handle/10757/625958/ Jim\%C3\%A9nezB_A.pdf?sequence=3\&isAllowed=y

- Ley del Impuesto a la Renta . (2004). https://www.sunat.gob.pe/legislacion/renta/ley/fdetalle. pdf

- López, D. (2017). Gastos deducibles. https://economipedia.com/definiciones/gastosdeducibles.html

- Narváez, V. (2018) Diseño de un procedimiento para la deducibilidad de las mermas y desmedros en el impuesto sobre las utilidades de las empresas. Unidad de Postgrado. Universidad Mayor de San Andrés. La Paz. https://repositorio.umsa.bo/bitstream/ handle/123456789/20120/T-I-

- Norma Internacional de Contabilidad 2 (s.f). Inventarios definiciones 6. https://www.mef.gob. pe/contenidos/conta_publ/con_nor_co/vigentes/nic/2_NIC.pdf

- Reglamento de la Ley del Impuesto a la Renta. (1994). https://www.sunat.gob.pe/legislacion/ renta/regla/cap6.pdf

- $\quad$ STC N. ${ }^{\circ}$ 2762-2002-AA/TC (Tribunal Constitucional 30 de enero de 2013).

- Tapia, L. (2014) Tratamiento contable de las mermas, en una empresa de ventas al detalle. Grado de Licenciado en Ciencias Administrativas. Universidad Academia de Humanismo Cristiano.

- Villanueva, W. (21.10.2020). Impuesto General a las Ventas. Aspectos Generales del IGV. Charla presentada en Instituto de Desarrollo Tributario Aduanero. Lima. Consulta: 22 de setiembre 2021. https://www.youtube.com/watch?v=zi68_vRPZfo

- Ynca, L y Gonzales, F. (2017) El Tratamiento de las Mermas y Desmedros en el Impuesto a la Renta: Principales Problemas y Propuestas de Solución. Grado de Maestro. Universidad de Lima. Lima. https://repositorio.ulima.edu.pe/bitstream/handle/20.500.12724/9536/ Ynca_C\%C3\%B3rdova_Lourdes_Patricia.pdf? sequence=1\&isAllowed=y

Fecha de recepción : 26 de octubre de 2021

Fecha de aceptación: 23 de noviembre de 2021 